\title{
OPTIMAL MAINTENANCE POLICY WITH MINIMAL REPAIR FOR STOCHASTICALLY FAILING SYSTEM
}

\author{
Kuniaki Tatsuno \\ Fumio Ohi \\ Osaka University \\ Osaka University \\ Toshio Nishida \\ Osaka University
}

(Received June 17, 1981; Final April 1, 1982)

Abstract We consider a Markovian deteriorating complex system which fails with state- dependent probability. The following two features on cost associated with maintaining such a complex system seem to be reasonable: Replacing a whole system at any failure ocassion is more expensive than minimally repairing and using it again. And a replacement at a failure is more costly than a planned replacement of an unfailed system.

This paper develops both countable infinite- and finite-state minimal repair models taking into account the above two features, and discusses a maintenance policy which minimizes the expected total discounted cost. It is shown that the optimal policy is of $(\mathrm{i}, \mathrm{I})$ type under some conditions on the transition probabilities and the cost structure.

\section{Introduction}

In maintaining a deteriorating complex system, the following two features on cost seem to be reasonable: A replacement of a whole system at any failure occasion is more expensive than minimally repairing and using it again. A replacement at a failure occasion is more costly than a planned replacement of an unfailed system.

Barlow and Hunter [1] introduced a minimal repair model taking into account the above situations, and discussed the optimality of so called Policy II (periodic replacement policy with minimal repair). After that, Policy III was proposed to improve Policy II [2], and $(t, T)$-Policy was studied to generalize Policy $I$ by introducing a breakdown cost [5]. In those models, the age of the system and/or the number of failures were used as a state variable, but no further information on the state of the system was available.

In this paper, we consider a similar minimal repair model, but the infor-- 
mation on the inner state of the system is assumed to be available. Moreover, the dynamic behavior of the inner state is supposed to be described by an infinite or finite state Markov chain. The infinite state model is intended to present a cumulative discrete damage model. The finite state model is purposed to study the case where the deterioration of performance is classified into finite levels. As a matter of convenience, we will call the underlying state of the system " the deterioration leve1 " in both cases. For a complex system such that a malfunction of any component of a system causes a system's failure, it is preferable to classify the failure states by the deterioration level of the system. We consider the following failure mechanism: At any instant after transition to the deterioration level $j$, the system fails with a known probability that depends on the level $j$. Then the state of the system is taken to be in failure with the deterioration level $j$. Possible maintenance actions are preventive replacement, emergency replacement and minimal repair. There are costs associated with each action. The purpose of this study is to investigate the structure of the maintenance policy minimizing the total expected discounted cost. Under some conditions on the transition probabilities and the cost structure, it is shown that an optimal policy has a form of ( $i, I$ ) type: Perform an emergency replacement at the first failure after the deterioration level exceeds the level $i$, and a minimal repair for the failure up to reaching the level i. Perform a preventive replacement at the first transition to the level which is greater than I without failure at any level between $i$ and $I$.

We will discuss an infinite state model in Sections 2, 3 and 4, and then a finite case in Section 5 .

\section{The Minimal Repair Model and Formulation}

Let $\{0,1,2, \cdots\}$ be a set of underlying "deterioration levels of the system, where "0" means that the system is new and "1", "2", .. represent the increasing deterioration levels of the system. The sequence of successive deterioration levels of the system is assumed to form a discrete Markov chain $\left\{X_{t}, t=0,1, \cdots\right\}$ with stationary transition probabilities $\left\{q_{i j}\right\}$.

$$
\operatorname{Pr}\left\{X_{t+1}=j \mid X_{t}=i\right\}=\left\{\begin{array}{l}
a_{i j}, i=0,1, \cdots, j=i, i+1, \cdots, \\
0, \text { otherwise. }
\end{array}\right.
$$

At the instant after transition from underlying deterioration level $i$ to level $j>i$, the system survives with probability $1-r_{j}$, and fails with proba- 
bility $r_{j}$

Assumption 1. (i) $\sum_{j=k}^{\infty} q_{i j}$ is nondecreasing in $i$ for $k=0,1, \cdots$. (ii) $q_{i i}, i \in S_{0}$ is nonincreasing in $i$.

(iii) $r_{j}$ is nondecreasing in $j$.

For convenience, we consider a Markov chain $\left\{y_{t}, t=0,1, \cdots\right\}$ instead of underlying process $\left\{X_{t}, t=0,1, \cdots\right\}$. The state space $\Omega=S_{o} u S_{f}$ is defined as

$$
\begin{aligned}
& S_{o}=\{0,1,2, \cdots\}: \text { Operable state space, } \\
& S_{f}=\left\{\delta_{1}, \delta_{2}, \cdots\right\}: \text { Failure state space, }
\end{aligned}
$$

where a state $i \in S_{0}$ means that the underlying deterioration level is $i$ and the system is operating, and a state $\delta_{i} \in S_{f}$ represents that the level is $i$ and the system is in failure. Transition probabilities are defined as follows: For $i=0,1, \cdots$,

$$
\begin{aligned}
& \operatorname{Pr}\left\{y_{t+1}=j \mid y_{t}=i\right\}=p_{i j}=\left\{\begin{array}{l}
q_{i j}\left(1-r_{j}\right), j \geq i+1, \\
q_{i i}, j=i, \\
0, \text { otherwise, }
\end{array}\right. \\
& \operatorname{Pr}\left\{y_{t+1}=\delta_{j} \mid y_{t}=i\right\}=q_{i \delta_{j}}=\left\{\begin{array}{l}
q_{i j}{ }^{r} j, j \geq i+1 \\
0, \text { otherwise }
\end{array}\right. \\
& \operatorname{Pr}\left\{y_{t+1}=\delta_{i} \mid Y_{t}=\delta_{i}\right\}=p_{\delta_{i} \delta}=1 \text {. }
\end{aligned}
$$

At the beginning of each period $t=0,1, \cdots$, one of possible maintenance actions is taken instantaneously. Either $a_{0}$ or $a_{2}$ is available on a state $i \in S_{0}$, where $a_{0}$ denotes a waiting action, that is, nothing is changed in the current system, and $a_{2}$ denotes the action that preventively replaces the system with a new one. We assume that the failed system has to be repaired or replaced immediately. Then either $a_{1}$ or $a_{2}$ is taken on a state $\delta_{i} \epsilon S_{f}$, where $a_{1}$ is a minimal repair action, that is, preserving the system at the same deterioration level $i$, it only removes the failure, and $a_{2}$ is the action that replaces the failed system with a new one. There are costs associated with the action taken: Minimal repair at a state $\delta_{i} \operatorname{costs} C_{\mathrm{m}}(i)$. Constant costs $C_{\mathrm{p}}$ and $\mathrm{C}_{\mathrm{e}}$ are incurred respectively to a preventive replacement and a replacement of the failed system.

Assumption 2. (i) $\left\{C_{\mathrm{m}}(i), i \geq 1\right\}$ is a bounded, nondecreasing sequence of: i. (ii) $0<\mathrm{C}_{\mathrm{p}} \leq \mathrm{C}_{\mathrm{e}}<\infty$. (iii) $0 \leq C_{\mathrm{m}}(i) \leq \mathrm{C}_{\mathrm{e}}$. 
Our goal is to find an optimal maintenance policy which minimizes the expected total cost discounted by $\alpha \in[0,1)$ over an infinite planning horizon.

The problem stated above is formulated by a discrete-time Markov decision process. Let $V(i)$ denote the expected total discounted cost incurred when the initial state is $i$ and an optimal policy is employed through the planning horizon. We note that $V(\cdot)$ is a bounded function on the state space because of Assumption 2 and $0 \leq 0<1$. Then $V(i)$ and $V\left(\delta_{i}\right)$ satisfy the following functional equations (see Theorem 6.1 in Ross [4] ):

where

$$
\begin{aligned}
& V(i)=\min \left\{\alpha W(i), C_{\mathrm{p}}+\alpha W(0)\right\}, i \in \mathrm{S}_{0}, \\
& V\left(\delta_{i}\right)=\min \left\{C_{\mathrm{m}}(i)+\alpha W(i), c_{\mathrm{e}}+\alpha W(0)\right\}, \delta_{i} \in \mathrm{S}_{\mathrm{f}},
\end{aligned}
$$

$$
W(i)=\sum_{j=i}^{\infty}\left\{p_{i j} V(j)+p_{i \delta_{j}} V\left(\delta_{j}\right)\right\}
$$

\section{An Optimal Policy Minimizing the Expected Total Discounted Cost}

In this section, we first consider such an n-stage problem that the planning horizon is just $\mathrm{n}$ periods. Let define $V_{n}(i)$ to be the expected total discounted cost when one starts from a state $i$ and employs an optimal policy through the remaining $n$ periods. Similar functional equations to $(2.1),(2.2)$ and (2.3) hold for the case.

where

$$
\begin{aligned}
& V_{n}(i)=\min \left\{\alpha W_{n-1}(i), c_{p}+\alpha W_{n-1}(0)\right\}, i \in S_{0}, \\
& V_{n}\left(\delta_{i}\right)=\min \left\{C_{m}(i)+\alpha W_{n-1}(i), c_{e}+\alpha W_{n-1}(0)\right\}, \delta_{i} \in S_{f},
\end{aligned}
$$

$$
W_{n}(i)=\sum_{j=i}^{\infty}\left\{p_{i j} V_{n}(j)+p_{i \delta_{j}} V_{n}\left(\delta_{j}\right)\right\}
$$

Lemma 1 . For $n=0,1, \cdots$, and $i=1,2, \cdots, V_{n}\left(\delta_{i}\right) \geq V_{n}(i)$.

Proof: From (3.1) and (3.2), there are four possible cases: $V\left(\delta_{i}\right)-V(i)$

$$
=\left\{\begin{array}{l}
C_{\mathrm{e}}-C_{\mathrm{p}}, \text { if } C_{\mathrm{e}}+\alpha W(0) \leq C_{\mathrm{m}}(i)+\alpha W(i) \text { and } C_{\mathrm{p}}+\alpha W(0) \leq \alpha W(i), \\
C_{\mathrm{m}}(i), \text { if } C_{\mathrm{m}}(i)+\alpha W(i) \leq C_{\mathrm{e}}+\alpha W(0) \text { and } \alpha W(i) \leq \mathrm{C}_{\mathrm{p}}+\alpha W(0), \\
C_{\mathrm{e}}+\alpha W(0)-\alpha W(i), \text { if } C_{\mathrm{e}}+\alpha W(0) \leq C_{\mathrm{m}}(i)+\alpha W(i) \text { and } \alpha W(i) \leq C_{\mathrm{p}}+\alpha W(0), \\
C_{\mathrm{m}}(i)+\alpha W(i)-C_{\mathrm{p}}-\alpha W(0), \text { if } C_{\mathrm{m}}(i)+\alpha W(i) \leq C_{\mathrm{e}}+\alpha W(0) \text { and } C_{\mathrm{p}}+\alpha W(0) \leq \alpha W(i) .
\end{array}\right.
$$


The statement of the lemma is obvious in the first two cases from Assumption 2 . In the third case, $C_{\mathrm{e}}+\alpha W(0)-\alpha W(i) \geq C_{\mathrm{e}}-C_{\mathrm{p}} \geq 0$ since $\alpha W(i) \leq C_{\mathrm{p}}+\alpha W(0)$. Similarly, $C_{\mathrm{m}}(i)+\alpha W(i)-C_{\mathrm{p}}-\alpha W(0) \geq C_{\mathrm{m}}(i) \geq 0$ in the last case since $C_{\mathrm{p}}+\alpha W(0) \leq \alpha W(i)$.

In order to prove Lemma 3 below, we prepare some notations and a lemma. Let $a_{i j}=1$ if $i=j ; a_{i j}=0$ if otherwise, and for two functions $h_{1}(j)$ and $h_{2}(j)$ put

$$
G_{i}(j)=\left\{\begin{array}{l}
{\left[1-\left(1-a_{i j}\right) r_{j}\right] h_{1}(j)+\left(1-a_{i j}\right) r_{j} h_{2}(j), \text { when } j \geq i} \\
0, \text { when }-1 \leq j<i,
\end{array}\right.
$$

for $i \in \mathrm{S}_{0}$. Let $\Delta_{i}(k)=G_{i}(k)-G_{i}(k-1)$ for $k=0,1, \cdots$.

Lemma 2. If functions $h_{i}(j), i=1,2$ satisfy the following two properties, (i) $h_{i}(j)$ is nondecreasing in $j(i=1,2)$, (ii) $0 \leq h_{1}(j) \leq h_{2}(j)$ for $j=1,2, \cdots$, then for any fixed $i$ (a) $\Delta_{i}(k)=\Delta_{i+1}(k)$ for $k \geq i+3$, (b) $\Delta_{i}(k) \geq 0$ for a11 $k$.

Proof: (a) is obvious. As for (b), it suffices to prove that $\Delta_{i}(k) \geq 0$ for $k \geq i$, since $\Delta_{i}(k)=0$ for $k<i$. Let us begin with $k=i$ and $i+1$. It easily follows that $\Delta_{i}(i) \geq 0$ and $\Delta_{i}(i+1) \geq 0$ from the properties (i) and (ii). Next for $k \geq i+2$,

$$
\begin{aligned}
\Delta_{i}(k)=\left(1-r_{k}\right) h_{1}(k)+r_{k} h_{2}(k)-\left(1-r_{k-1}\right) h_{1}(k-1)-r_{k-1} h_{2}(k-1) \\
\quad \geq\left(r_{k-1}-r_{k}\right) h_{1}(k-1)+\left(r_{k}-r_{k-1}\right) h_{2}(k-1) \\
=\left(r_{k}-r_{k-1}\right)\left(h_{2}(k-1)-h_{1}(k-1)\right) \geq 0 .
\end{aligned}
$$

The first inequality follows from the property (i). Assumption 1-(ii) and the property (ii) guarantee the second inequality.

Lemma 3. For any $n=0,1, \cdots, W_{n}(i)$ is a monotone nondecreasing function of $i \in S_{0}$.

Proof: Using an induction, we sha11 prove that $W_{n}(i)$ as well as $V_{n}(i)$ and $V_{n}\left(\delta_{i}\right)$ is nondecreasing in $i$.

When $n=0$, the lemma is true since $W_{0}(i)=V_{0}(i)=V_{0}\left(\delta_{i}\right)=0$ for all $i$. We assume that $W_{n-1}(i)$ is nondecreasing in $i$. Considering the equations (3.1), (3.2) and Lemma 1 , it follows that $V_{n}(i)$ and $V_{n}\left(\delta_{i}\right)$ satisfy the two properties required for $h_{1}(i)$ and $h_{2}(i)$ in Lemma 2 . Let us define

$$
G_{i, n}(j)=\left\{\begin{array}{l}
{\left[1-\left(1-a_{i j}\right) r_{j}\right] V_{n}(j)+\left(1-a_{i j}\right) r_{j} V_{n}\left(\delta_{j}\right), j \geq i,} \\
0,-1 \leq j<i,
\end{array}\right.
$$

and $\Delta_{i, n}(k)=G_{i, n}(k)-G_{i, n}(k-1)$, then two assertions of Lemma 2 hold for $\Delta_{i, n}(k)$. Since $W_{n}(i)$ is rewritten as $W_{n}(i)=\sum_{j=i}^{\infty} q_{i j} G_{i, n}(j)$, we have 


$$
\begin{aligned}
& W_{n}(i+1)-W_{n}(i)=\sum_{j=i+1}^{\infty} q_{i+1 j} \sum_{k=0}^{j} \Delta_{i+1, n}(k)-\sum_{j=i} q_{i j} \sum_{k=0}^{j} \Delta_{i, n}(k) \\
& =\sum_{k=i+1}^{i+2} \Delta_{i+1, n}(k) \sum_{i=k}^{\infty} q_{i+1 j}-\sum_{k=i}^{i+2} \Delta, n(k) \sum_{j=k}^{\infty} q_{i j} \\
& +\sum_{k=i+3^{\Delta} i, n}^{\infty}(k) \sum_{j=k}^{\infty}\left(q_{i+1 j}-q_{i j}\right) \\
& \geq \Delta_{i+1, n}(i+2) \sum_{j=i+2}^{\infty} q_{i+1 j}{ }^{-\Delta} i, n(i+1) \sum_{j=i+1}^{\infty} q_{i j} \\
& -\Delta_{i, n}{ }^{(i+2)} \sum_{j=i+2}^{\infty} q_{i j}+\Delta_{i+1, n}{ }^{(i+1)-\Delta_{i, n}}{ }^{(i)} \\
& =\left\{G_{i+1, n}(i+2)-G_{i, n}(i+1)\right\} \sum_{j=i+2}^{\infty}\left(q_{i+1 j}-q_{i j}\right)+\left\{V_{n}(i+1)\right. \\
& \left.-V_{p i}(i)\right\} q_{i i}+r_{i+1}\left\{V_{n}\left(\delta_{i+1}\right)-V_{n}(i+1)\right\}\left(q_{i i}-q_{i+1 i+1}\right)
\end{aligned}
$$

$\geq 0$.

The first inequality results from $\sum_{k=i+3^{\Delta} i, n}^{\infty}(k) \sum_{j=k}^{\infty}\left(q_{i+1 j}-q_{i j}\right) \geq 0$. The second inequality is easily seen from Lemmas 1,2 and Assumption 1-(ii). Thus, $W_{n}(i)$ is nondecreasing in $i$ for all $n$.

Let the set $A_{o}$ and $A_{f}$ be such that

$$
\begin{aligned}
& A_{0}=\left\{i \in S_{0}: \alpha[W(i)-W(0)]>C_{p}\right\}, \\
& A_{f}=\left\{\delta_{i} \in S_{f}: \alpha[W(i)-W(0)]>C_{e}-C_{m}(i)\right\} .
\end{aligned}
$$

Considering the fact that $\lim _{n \rightarrow \infty} W_{n}(i)=W(i)$ (see, for example, Sec.6 in Ross [4]), the next theorem directly follows from Lemma 3.

Theorem 1. Let $i^{*}$ and $I^{*}$ be the number such that $I *=\inf \left\{i: i \in A_{0}\right\}$ and $i^{*}=\inf \left\{i: \delta_{i} \in A_{f}\right\}$. We use the convention that $i^{*}$ (or $\left.I^{*}\right)=\infty$ if $A_{o}$ (or $A_{f}$ ) is empty. Then under Assumptions 1 and 2, an optimal maintenance policy is to be of the form:

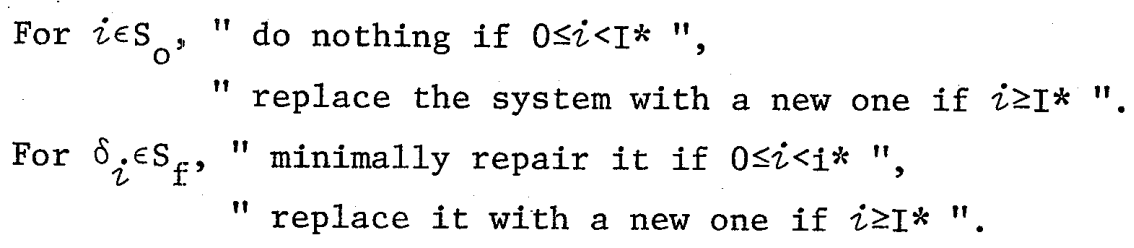

Now, we will investigate the relation between the cost structure and the form of an optimal (i,I) type policy. For the sake of simplicity, we restrict our concern to the case where $C_{\mathrm{m}}(i)=\mathrm{C}_{\mathrm{m}}$ for all $i$.

case $I: \quad i *=1$ if $C_{m}=C_{e}$. (Simple preventive replacement case)

This follows from (2.2) and Lemma 3.

Case II: $i^{*<I^{*}}$ if $\mathrm{C}_{\mathrm{e}}-\mathrm{C}_{\mathrm{p}}<\mathrm{C}_{\mathrm{m}}$.

To prove the above, it suffices to show that $k \notin A_{0}$ for any $k$ such that $\delta_{k} \notin A_{f}$. From the definition of $A_{f}, \alpha W(k) \leq C_{e}-C_{m}+\alpha W(0)$ for any $\delta_{k} \notin A_{f}$. Then, we have 
$\alpha W(k)<\mathrm{C}_{\mathrm{p}}+\alpha W(0)$, i.e., $k \xi \mathrm{A}_{0}$.

Case III: $i^{*}=I^{*}$ if $\mathrm{C}_{\mathrm{e}}-\mathrm{C}_{\mathrm{p}}=\mathrm{C}_{\mathrm{m}}$.

If $\delta_{k} \notin A_{f}$, then $\alpha W(k) \leq C_{p}+\alpha W(0)$, i.e., $k \notin A_{0} \cdot$ On the other hand, if $k \in A_{0}$, then $\mathrm{C}_{\mathrm{m}}+\alpha W(k) \leq \mathrm{C}_{\mathrm{p}}+\alpha W(0)$, i.e., $\delta_{k} \in \mathrm{A}_{\mathrm{f}}$. Thus, $i *=\mathrm{I} *$.

Case $\mathrm{IV}: \mathrm{I}^{*=\infty}$ if $\mathrm{C}_{\mathrm{e}}=\mathrm{C}_{\mathrm{p}}$.

Let us define $\pi$ to be the policy that takes action $a_{0}$ up to the first failure and thereafter coincides an optimal policy. Letting $Q_{\pi}^{n}\left(i, \delta_{j}\right)$ be the probability that the process first enters a state $\delta_{j} \in S_{f}$ at the $n$-th step after starting from $i \in S_{0}$ when one uses the policy $\pi$, then the total expected discounted cost $V_{n}(i)$ is given by

$$
\begin{aligned}
V_{\pi}(i) & =\sum_{j=i+1}^{\infty} \sum_{n=1}^{\infty} \alpha^{n} \cdot Q_{\pi}^{n}\left(i, \delta_{j}\right) \cdot V\left(\delta_{j}\right) \\
& \leq\left\{c_{p}+\alpha W(0)\right\} \sum_{j=i+1}^{\infty} \sum_{n=1}^{\infty} \alpha^{n} \cdot Q_{\pi}^{n}\left(i, \delta_{j}\right) \\
& <c_{p}+\alpha W(0) .
\end{aligned}
$$

On the other hand, $V(i) \leq V_{\pi}(i)$ since the policy $\pi$ is not optimal. Hence, we have $V(i)<\mathrm{C}_{\mathrm{p}}+\alpha W(0)$ for $a l 1 i \in \mathrm{S}_{\mathrm{O}}$, that shows $\mathrm{I}^{*}=\infty$.

\section{Expected Average Cost Criterion}

In this section, we demonstrate that an optimal maintenance policy minimizing the expected average cost exists in the class of (i,I) type policies under Assumptions 1 and 2 .

Let $\Phi_{\pi}(i)$ be the expected average cost when a policy $\pi$ is employed with the initial state $i$.

Theorem 2. Under Assumptions 1 and 2, there exists an optima1 maintenance policy $\pi^{*}$ which minimizes the expected average cost in the class of (i, I) type policies.

Proof: From (2.1), (2.2) and the fact $V(0)=\alpha W(0)$, we have inequalities:

$$
\begin{aligned}
& 0 \leq V(i)-V(0) \leq \mathrm{C}_{\mathrm{p}} \text { for a11 } i \in \mathrm{S}_{\mathrm{o}} \text { and } \alpha \in[0,1), \\
& 0 \leq V\left(\delta_{i}\right)-V(0) \leq \mathrm{C}_{\mathrm{e}} \text { for al1 } \delta_{i} \in \mathrm{S}_{\mathrm{f}} \text { and } \alpha \in[0,1),
\end{aligned}
$$

which assure the application of Theorem 1.1 in Ross [3] to our problem. By virtue of the theorem, there exists a constant $g$ and an increasing functions $U(i)$ and $U\left(\delta_{i}\right)$ such that

$$
\begin{aligned}
& g+U(i)=\min \left\{\tilde{W}(i), c_{\mathrm{p}}+\tilde{W}(0)\right\}, i \in \mathrm{S}_{\mathrm{o}}, \\
& g+U\left(\delta_{i}\right)=\min \left\{C_{\mathrm{m}}(i)+\widetilde{W}(i), \mathrm{c}_{\mathrm{e}}+\tilde{W}(0)\right\}, \delta_{i} \in \mathrm{S}_{\mathrm{f}},
\end{aligned}
$$


where $\tilde{W}(i)=\sum_{j=i}^{\infty} q_{i j}\left\{\left[1-\left(1-a_{i j}\right) r_{j}\right] U(j)+\left(1-a_{i j}\right) r_{j} U\left(\delta_{j}\right)\right\}$. Moreover, Theorem 1.2 in Ross [3] ensures that an optimal policy for the expected average cost is to be the policy which chooses the minimizing action in the right hand side of (4.1) and (4.2). Thus, similarly to the expected total discounted cost case, it can be shown that the structure of the optimal policy is to be (i,I), type.

In the expected average cost case, the elementary renewal theorem is helpful to obtain an optimal (i,I) policy and the expected average cost under the policy. Let $I$ denote the class of ( $i, I)$ type policies (where $i \leq I$ ). The expected average cost when one employs $\pi \in \Pi$ and initiates with a new system is given by

$$
\Phi_{\pi}(0)=\mathrm{E}_{\pi} R / \mathrm{E}_{\pi} N
$$

where $\mathrm{E}_{\pi} N$ represents the expected time interval between replacements under the policy $\pi$, and $\mathrm{E}_{\pi} R$ denotes the expected cumulative cost incurred during the interval. According to Theorem 2, an optimal expected average cost when one starts with a new system, $\Phi *(0)$, is given by

$$
\Phi *(0)=\text { inf: } \pi \in \Pi^{\mathrm{E}} \pi^{R / \mathrm{E}} \pi^{N}
$$

\section{Minimal Repair Model with Finite States}

We consider the same minimal repair model stated in Section 2 except for the state space. "Deterioration levels" of the system's performance can be classified into one of $0,1, \cdots, n-1$. Let us define $\delta_{1}, \delta_{2}, \cdots, \delta_{n}$ to represent failure states. $\delta_{i}, i=1,2, \cdots, \mathrm{n}-1$, represents that the system is in failure at level $i . \delta_{i}$ stands for a complete failure state, and thus, it is assumed that the system is replaced at this state without any consideration. Then we construct a Markov chain $\left\{\bar{Y}_{t}, t=0,1, \cdots\right\}$ with state space $\bar{\Omega}_{\Omega}=\overline{\mathrm{S}}_{\mathrm{o}} u \overline{\mathrm{S}}_{\mathrm{f}}$, where $\overline{\mathrm{S}}_{\mathrm{o}}=$ $\{0,1, \cdots, n-1\}$ and $\bar{S}_{f}=\left\{\delta_{1}, \delta_{2}, \cdots, \delta_{n}\right\}$. Let us assume that the transition probabilities of $\left\{\bar{Y}_{t}, t=0,1, \cdots\right\}$ are given by

$$
\begin{aligned}
& \operatorname{Pr}\left\{\bar{y}_{t+1}=j \mid \bar{y}_{t}=i\right\}=\left\{\begin{array}{l}
q_{i j}\left(1-r_{j}\right), i=0,1, \cdots, \mathrm{n}-2 ; j=i+1, i+2, \cdots, \mathrm{n}-1, \\
q_{i i}, i=0,1, \cdots, \mathrm{n}-2 ; j=i, \\
1-r_{\mathrm{n}}, i=j=\mathrm{n}-1, \\
0, \text { otherwise, }
\end{array}\right. \\
& \operatorname{Pr}\left\{\bar{y}_{t+1}=\delta, \mid \bar{Y}_{t}=i\right\}=\left\{\begin{array}{l}
q_{i j} j_{j}, i=0,1, \cdots, \mathrm{n}-2 ; j=i+1, i+2, \cdots, \mathrm{n}-1, \\
r_{n}, i=\mathrm{n}-1 ; j=\mathrm{n}, \\
0, \text { otherwise. }
\end{array}\right.
\end{aligned}
$$


Assumption $\overline{1}$. (i) $\sum_{j=k}^{n-1} q_{i j}$ is nondecreasing in $i$ for $k=0,1, \cdots, n-1$.

(ii) $q_{i i}$ is nonincreasing in $i$.

(iii) $r_{j}$ is nondecreasing in $j$.

Let us define $\bar{V}(\cdot)$ which corresponds to $V(\cdot)$ in the infinite model, then

$$
\begin{aligned}
& \bar{V}(i)=\min \left\{\alpha \bar{W}(i), C_{\mathrm{p}}+\alpha \bar{W}(0)\right\}, i \in \overline{\mathrm{S}}_{\mathrm{o}}, \\
& \bar{V}\left(\delta_{i}\right)=\min \left\{C_{\mathrm{m}}(i)+\alpha \bar{W}(i), \mathrm{C}_{\mathrm{e}}+\alpha \bar{W}(0)\right\}, i=1,2, \cdots, \mathrm{n}-1, \\
& \bar{V}\left(\delta_{n}\right)=\mathrm{C}_{\mathrm{e}}+\alpha \bar{W}(0),
\end{aligned}
$$

where

$$
\bar{W}(i)=\left\{\begin{array}{l}
\sum_{j=i}^{n-1} q_{i j}\left\{\left[1-\left(1-a_{i j}\right) r_{j}\right] \bar{V}(j)+\left(1-a_{i j}\right) r_{j} \bar{V}\left(\delta_{j}\right)\right\}, i=0,1, \cdots \mathrm{n}-2, \\
\left(1-r_{n}\right) \bar{V}(\mathrm{n}-1)+r_{n} \bar{V}\left(\delta_{n}\right), i=\mathrm{n}-1 .
\end{array}\right.
$$

We are much concerned about the structure of optimal policies; that is, " Is there an (i,I) type optimal policy in the finite state model ? ". Our answer is affirmatively given by the next theorem.

Theorem 3. Under Assumptions $\bar{I}$ and 2, an optimal policy is to be an (i,I) type policy.

Proof: It suffices to prove that $\bar{W}(i)$ is nondecreasing in $i$. Employing the same way as the proof of Lemma 3 , it is easily shown that $\bar{W}(i+1) \geq \bar{W}(i)$ for $i=0,1, \cdots, n-2$. We will prove $\bar{W}(\mathrm{n}-1) \geq \bar{W}(\mathrm{n}-2)$ by restricting the planning horizon. The notations used here are similar to those defined in the proof of Lemma 3. Obvious $1 \mathrm{y}, \bar{W}_{0}(\mathrm{n}-1)=\bar{W}_{0}(\mathrm{n}-2)=0$. We assume that $\bar{W}_{m-1}(\mathrm{n}-1) \geq \bar{W}_{m-1}(\mathrm{n}-2)$, then $\bar{V}_{m}(\mathrm{n}-1) \geq \bar{V}_{m}(\mathrm{n}-2)$ from (5.1). When the remaining periods are $m$,

$$
\begin{aligned}
\bar{W}_{m}(\mathrm{n}-1)-\bar{W}_{m}(\mathrm{n}-2)= & \left(1-r_{\mathrm{n}}\right) \bar{V}_{m}(\mathrm{n}-1)+r_{\mathrm{n}} \bar{V}_{m}\left(\delta_{\mathrm{n}}\right)-q_{\mathrm{n}-2 \mathrm{n}-2} \bar{V}_{m}(\mathrm{n}-2) \\
& -q_{\mathrm{n}-2 \mathrm{n}-1}\left[\left(1-r_{\mathrm{n}-1}\right) \bar{V}_{m}(\mathrm{n}-1)+r_{\mathrm{n}-1} \bar{V}_{m}\left(\delta_{\mathrm{n}-1}\right)\right] \\
\geq & \left(r_{\mathrm{n}}-q_{\mathrm{n}-2 \mathrm{n}-1^{r} \mathrm{n}-1}\right)\left[\bar{V}_{m}\left(\delta_{\mathrm{n}-1}\right)-\bar{V}_{m}(\mathrm{n}-1)\right] \geq 0,
\end{aligned}
$$

since $\bar{V}_{m}\left(\delta_{\mathrm{n}}\right) \geq \bar{V}_{m}\left(\delta_{\mathrm{n}-1}\right) \geq \bar{V}_{m}(\mathrm{n}-1)$ and $q_{\mathrm{n}-2 \mathrm{n}-2}=1-q_{\mathrm{n}-2 \mathrm{n}-1}$. Considering the fact that $\lim _{m \rightarrow \infty} \bar{W}_{m}(i)=\bar{W}(i)$ for all $i \in \mathrm{S}_{0}$, then the theorem follows.

\section{Concluding Remarks}

In this paper, we discussed the structure of optimal policy for the Markovian deteriorating system with countable infinite or finite state space. As a result, some sufficient conditions under which an optimal policy is to be the form of ( $i, I$ ) type are Assumptions 1 and 2. We note that these assup- 
tions seem to be reasonable in many real situations.

It should be mentioned about the transition from state $i$ to state $\delta_{i}$. Owing to our modeling of failure mechanism, such a transition is not allowed in our model. One may, however, assert that the failure of the system will occur without regard to the transition of the underlying deterioration level. If the transition from $i$ to $\delta_{i}$ with positive probability is taken into account, then the condition, nonincreasing $q_{i i}$ in $i$, is omitted from the sufficient condition for the optimality of (i,I) type policy.

\section{References}

[1] Barlow, R. and Hunter, L.: Optimum Preventive Maintenance Policies. Operations Research, Vo1.8(1960), 90-100.

[2] Morimura, H.: On some Preventive Maintenance Policies for IFR. Journal. of the Operations Research Society of Japan, Vol.12(1970), 94-124.

[3] Ross, S.M.: Non-Discounted Denumerable Markovian Decision Models. The Annals of Mathematical Statistics, Vo1.39(1968), 412-423.

[4] Ross, S.M.: Applied Probability Models with Optimization Applications. Holden-Day, 1970.

[5] Tahara, A. and Nishida, T.: Optimal Replacement Policy for Minima1 Repair Mode1. Joumal of the Operations Research Society of Japan, Vo1.18(1975), $113-124$.

\footnotetext{
Kuniaki TATSUNO: Department of Applied Physics, Faculty of Engineering, Osaka University, Yamada-Oka, Suita, Osaka, 565, Japan.
} 


\section{劣化システムに対する, 小修理を考慮した最適保全政策}

$\begin{array}{ccccc}\text { 大阪大学 竜 } \text { 野 邦 明 } \\ \text { 大 } & \text { 鋳 史 男 } \\ & \text { 西 } \text { 田 俊 夫 }\end{array}$

劣化の様相がマルコフ連鎖によって記述される複雑なシステムを考える。システムの劣化状態が $i$ になったとする。乙のとき, システムは, 状態 $i$ に依存した確率で, 瞬間的に故障するすのとす る。乙の故障状態を $\delta_{i}$, 劣化状態 $i$ での故障, によって区別する。

この論文では, システムに対する保全手段として, 予防取替, 及び故障取替に加えて, 小修理を とりうるあのとし，割引された総期待コストを最小にする保全政策が議論される。

保全コストと, 劣化状態推移確率とに関するある条件の下で, 最適な保全政策は $(i, \mathrm{I})$ 型 政 策であるととが示される。 